\title{
Dysferlinopathy: A clinical and histopathological study of 28 patients from India
}

\author{
A. Nalini, N. Gayathri ${ }^{1}$ \\ Departments of Neurology and ${ }^{1}$ Neuropathology, National Institute of Mental Health and Neurosciences, Bangalore, Karnataka, India
}

\begin{abstract}
Background: Miyoshi myopathy (MM) and limb girdle muscular dystrophy (LGMD2B) are distinct clinical entities because different muscle groups are involved at the onset. We describe the clinical features in 28 patients with dysferlin deficiency confirmed by muscle immunohistochemistry (IHC). Settings and Design: A case series from a tertiary national referral center for neurological disorders. Materials and Methods: Patients with classical phenotype of MM and LGMD2B underwent a thorough phenotypic characterization followed by muscle histopathological study including IHC for dysferlin deficiency. Results: There were 28 patients (20 men and eight women) presenting with manifestations of distal myopathy or LGMD2B and had absence of dysferlin staining on IHC. Patients presented predominantly with distal myopathy of Miyoshi type (MM) or proximal LGMD type and were diagnosed to have dysferlinopathy on IHC. Two patients had the proximodistal form and two had onset as tibial muscular dystrophy. The main clinical features in these patients were onset in late adolescence or early adulthood (mean age of onset for MM was 22.0 \pm 6.7 years and for LGMD2B $19.4 \pm 5.1$ years). There was early and predominant involvement of the posterior compartment muscles of the leg or proximal pelvic girdle muscles, dystrophic features with necrotic regeneration pattern without vacuoles on muscle biopsy and markedly elevated serum creatine kinase values with mean of $10033.8 \pm 9283 \mathrm{IU} / \mathrm{l}$ (range 402-27460). Consanguinity was reported in $46.4 \%$. The mean duration of illness was $6.4 \pm 4.2$ years. Dysferlinopathies formed nearly one-fourth of our patients with LGMD. Conclusion: In our experience dysferlinopathies was not an uncommon form of LGMD.
\end{abstract}

Key words: Distal myopathy, dysferlinopathy, LGMD2B, Miyoshi myopathy

\section{Introduction}

Miyoshi myopathy (MM) and limb girdle muscular dystrophy (LGMD2B) are distinct clinical entities because different muscle groups are involved at the onset. Miyoshi myopathy is an autosomal recessive/sporadic, early adult onset distal myopathy and was first described in 1967 and thereafter most cases have been reported from Japan ${ }^{[1-3]}$ and also from other countries. ${ }^{[4-6]}$ Miyoshi myopathy occurs between 15 and 25 years of age ${ }^{[3,7]}$ and one of the first characteristics is weakness and atrophy of the calf muscles, preventing patients from standing on their toes. The serum creatine kinase (CK) activity is always markedly elevated to as much as $10-150$ times. ${ }^{[7]}$ Limb girdle muscular dystrophy was first defined as an entity in 1994; it also has autosomal recessive inheritance, begins predominantly with proximal muscle weakness, beginning between ages 15 and 25 years, adult onset, slow progression and with marked elevation in muscle CK levels. ${ }^{[8-11]}$ Both MM and LGMD2B have similar features, however, the pelvic girdle distribution of weakness distinguishes LGMD2B from MM. It is known that both LGMD2B and MM exist in the same family ${ }^{[4]}$ Both MM and LGMD2B are demonstrated to be allelic disorders with both being linked to the same locus on Chromosome 2p13 ${ }^{[8,12,13]}$ and include the DYSF gene encoding the protein dysferlin. ${ }^{[14,15]}$ In the present study, we report the clinical characteristics, histopathological and immunohistochemical findings in 28 patients with dysferlinopathy.

\section{Materials and Methods}

Twenty-eight patients confirmed to have dysferlin deficiency by immunostaining were included in this study. Patients were seen between 2005 and 2007 at the National Institute of Mental Health and Neurosciences, Bangalore, India, a tertiary national referral center for neurological disorders. Patients with clinical picture of LGMD or distal myopathy had undergone thorough phenotypic characterization and were subjected to a muscle biopsy. Various immunostaining (all NCL products from Novocastra, 
UK) including dysferlin, sarcoglycans $(\alpha, \beta, \gamma, \delta)$, merosin, dystroglycans and dystrophin $(1,2,3)$ were performed as primary and HRP tagged LSAB as secondary antibody in all muscle samples.

All 28 patients had undergone muscle biopsy and the specimens were taken from: biceps $(=17)$, quadriceps $(=9)$, hamstrings $(=1)$, gastrocnemius $(=1)$. Processing and staining were done according to routine methods. Assessment was by routine light microscopy and abnormalities were recorded.

Those with pure dysferlin deficiency on immunohistochemistry (IHC) were analyzed for their clinical characteristics and the medical records of these patients were scrutinized and detailed clinical information was retrieved retrospectively from the records and then compiled by entry into SPSS Version 13. All patients had undergone thorough clinical examination with recording of details of muscle involvement according to the Medical Research Council (MRC) grading scale, serum creatine kinase (CK) levels, conventional needle electromyography with nerve conduction studies and open muscle biopsy. Patients with a limb girdle syndrome were included in the panel of immunostaining which included dysferlin stain and those who showed a total loss of dysferlin expression evidenced by IHC on muscle biopsy were analyzed.

\section{Clinical examination}

All patients included in this study were examined by neurologists. The history included onset of illness, distribution of weakness, atrophy, hypertrophy, course of the disease and family history. Muscle involvement was evaluated clinically using MRC grading scale. Ability to stand on tiptoes and to hop was recorded. Detailed family history and a pedigree diagram were available for most families.

\section{Laboratory investigations}

Routine blood investigations and CK level were done in all. Conventional needle electromyography was performed in one upper and one lower limb and motor and sensory conduction studies were done in all. Cardiac evaluation with electrocardiography and 2D Echocardiogram were done in certain patients.

\section{Statistics}

The data was analyzed using descriptive statistics such as mean standard deviation for continuous variables and frequency percentage for categorical variables. Comparison between the different phenotypes was carried out by independent sample 't' test for continuous variables and Fisher's exact test for categorical variables $(P \leq 0.05)$

\section{Results}

\section{Clinical findings}

Twenty (71.4\%) men and eight (28.6\%) women were included in the study. The mean age at the time of evaluation was $27.9 \pm 7.7$ years (range 14-45). All patients had presented with progressive muscle weakness. Consanguinity was seen in 13(46.4\%) families. The pedigree diagrams of two representative families are depicted in Figures 1 and 2. Eight of the 28 patients had positive family history and in six patients a second sibling was affected and in two more families a third sibling was affected. The mean age of onset of muscle complaints was $21.4 \pm 6.0$ years (range 11-37), among men $22.7 \pm 5.9$ years (range 14-37) and among women $18.1 \pm 5.5$ years (11-28). The mean duration of illness was $6.4 \pm 4.2$ years (range 1-15). In 22 patients, the onset was between 15 and 30 years, in four patients before 15 years and in only two patients the first symptom at onset was after 30 years of age. The disease typically started with calf weakness and atrophy in one or both legs in 12 (42.9\%) patients [Figure 3] and in another 12 (42.9\%) patients the initial muscle weakness was of limb girdle type with onset as lower limb proximal muscle weakness. In two (7.1\%) patients the first symptom was

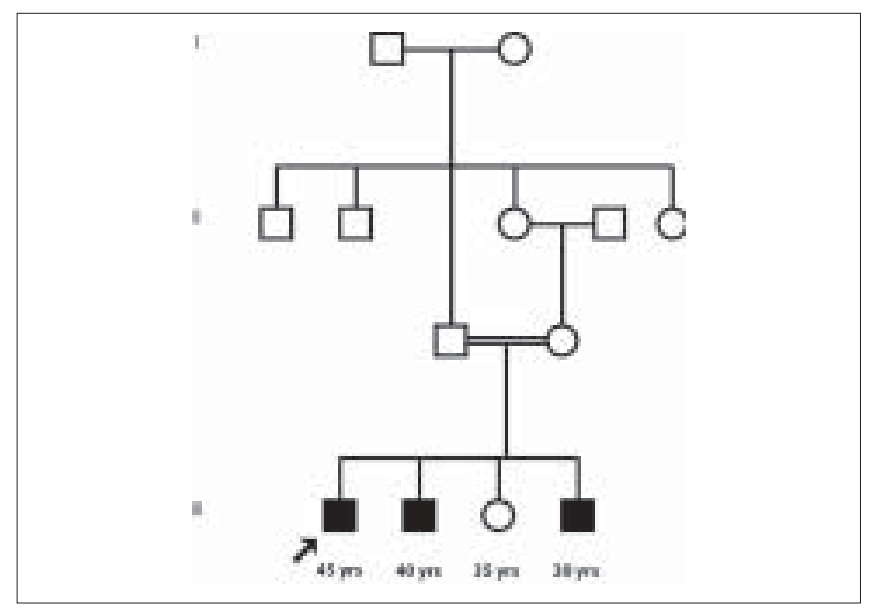

Figure 1: The solid symbols represent members affected with dysferlinopathy. There was intrafamilial variability. Propositus and the last sibling were wheelchair-bound. The second affected sibling was still ambulant. Biopsy was performed only in the proband

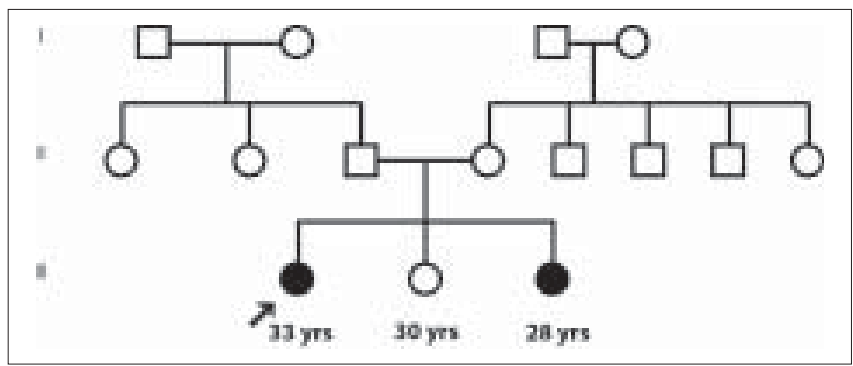

Figure 2: Solid symbols indicate those affected with dysferlinopathy. All the three sisters had multinodular goiter with thyrotoxicosis 
progressive weakness of the tibialis anterior muscle with foot drop, which later progressed to involve the proximal muscles also. Their ages at onset were 23 and 26 years. In another two $(7.1 \%)$ patients the illness was of proximodistal type with onset of weakness in proximal and distal muscles simultaneously and their ages at onset were 21 and 32 years [Figure 4]. Summary of the clinical findings are represented in Table 1. The muscle weakness was progressive in all patients at the

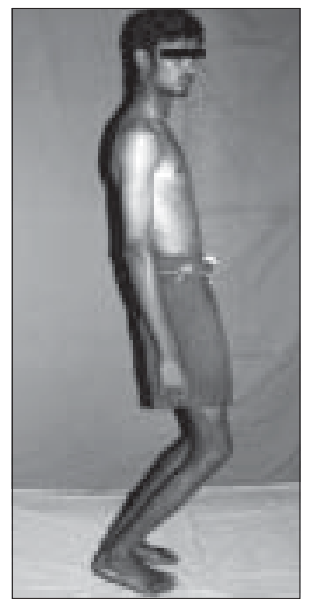

Figure 3: Patient with Miyoshi myopathy. Has severe wasting of calf muscles and difficulty to stand on toes

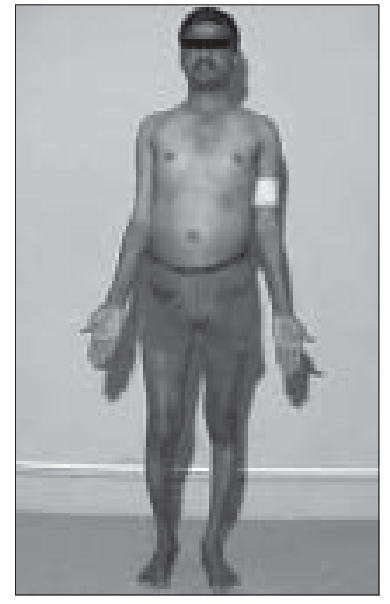

Figure 4: Patient with proximodistal form with early severe disability was just able to stand independently. Required assistance to walk five years after onset time of evaluation. All were ambulant except for two patients who were wheelchair-bound and they reached this state nine and 15 years after onset. In one of our families two of the three sisters had LGMD2B and interestingly all three had multinodular goiter with thyrotoxicosis [Figure 2]. Comparison of the clinical features and laboratory findings were made between MM, LGMD2B, proximodistal form and anterior tibial form [Table 2]. Among patients with MM and LGMD2B

\begin{tabular}{|c|c|}
\hline \multicolumn{2}{|c|}{$\begin{array}{l}\text { Table 1: Salient clinical manifestations in } 28 \text { patients with } \\
\text { dysferlinopathy }\end{array}$} \\
\hline Parameter & $\mathbf{N}(\%)$ \\
\hline Age of onset (years) (Mean \pm SD) & $21.4 \pm 6.0$ \\
\hline Age at presentation (years) (Mean $\pm S D)$ & $27.9 \pm 7.7$ \\
\hline Duration of illness (years) (Mean \pm SD) & $6.4 \pm 4.2$ \\
\hline Males & $20(71.4)$ \\
\hline Consanguinity & $13(46.4)$ \\
\hline \multicolumn{2}{|l|}{ Symptom at onset } \\
\hline Unable to stand on toes & $12(42.9)$ \\
\hline LL proximal weakness & $12(42.9)$ \\
\hline Ankle dorsiflexor weakness & $2(7.1)$ \\
\hline Proximodistal weakness & $2(7.1)$ \\
\hline \multicolumn{2}{|l|}{ Other symptoms } \\
\hline Falls & $16(57.1)$ \\
\hline Muscle pains & $13(46.4)$ \\
\hline Cramps & $3(10.7)$ \\
\hline Positive family history & $8(28.6)$ \\
\hline \multicolumn{2}{|l|}{ Neurological findings } \\
\hline Neck flexor weakness & $10(35.7)$ \\
\hline \multicolumn{2}{|l|}{ Upper limbs weakness } \\
\hline Shoulder girdle & $15(53.6)$ \\
\hline Arm & $14(50.0)$ \\
\hline Distal weakness & $9(32.1)$ \\
\hline Hand grip & $9(32.0)$ \\
\hline \multicolumn{2}{|l|}{ Lower limbs weakness } \\
\hline Pelvic girdle & $26(92.9)$ \\
\hline Thigh & $25(89.2)$ \\
\hline Distal muscles & $17(60.7)$ \\
\hline Gastocnemius & $17(60.7)$ \\
\hline Tibialis anterior & $15(53.6)$ \\
\hline Wasting of calves & $16(57.1)$ \\
\hline \multicolumn{2}{|l|}{ Deep tendon reflexes } \\
\hline \multicolumn{2}{|l|}{ Upper limbs } \\
\hline Sluggish to absent & $13(46.4)$ \\
\hline \multicolumn{2}{|l|}{ Lower limbs } \\
\hline \multicolumn{2}{|l|}{ Sluggish to absent } \\
\hline Knee reflex & $19(67.9)$ \\
\hline Ankle reflex & $22(78.6)$ \\
\hline
\end{tabular}

Where percentage is not applicable the expression is indicated beside the variable

Table 2: Comparison of clinical features in the four different phenotypes of dysferlinopathy

\begin{tabular}{|c|c|c|c|c|c|}
\hline Variable & $\begin{array}{c}\text { MM } \\
(n=12)\end{array}$ & $\begin{array}{l}\text { LGMD } \\
(\mathrm{n}=12)\end{array}$ & (P-value) & $\begin{array}{l}\text { Proximodistal } \\
\quad(n=2)\end{array}$ & $\begin{array}{l}\text { Tibial dystrophy } \\
\qquad(\mathrm{n}=2)\end{array}$ \\
\hline Age at presentation (mean \pm SD) (years) & $28.8 \pm 8.9$ & $24.9 \pm 6.1$ & 0.21 & $32.0 \pm 5.7$ & $35.5 \pm 0.7$ \\
\hline Age at onset (mean $\pm S D$ ) (years) & $22.0 \pm 6.7$ & $19.4 \pm 5.1$ & 0.35 & $24.5 \pm 2.1$ & $26.5 \pm 7.8$ \\
\hline $\mathrm{M}: \mathrm{F}$ & 10:2 & $7: 5$ & 0.37 & $2: 0$ & $2: 0$ \\
\hline Consanguinity & 5 & 5 & & 2 & 1 \\
\hline Duration of illness (mean $\pm S D$ ) (years) & $6.75 \pm 4.2$ & $5.46 \pm 3.8$ & 0.67 & $7.5 \pm 3.5$ & $9.0 \pm 8.4$ \\
\hline CK value $(\mathrm{U} / \mathrm{I})($ mean $\pm \mathrm{SD})$ & $10036.0 \pm 9948.4$ & $11381.5 \pm 9882.2$ & & $5461.5 \pm 6984.0$ & $6505.5 \pm 5161.0$ \\
\hline Upper limb distal & & & & & \\
\hline $\begin{array}{l}\text { Muscles affected } \\
\text { Lower limb distal }\end{array}$ & 7 & 0 & 0.037 & 2 & - \\
\hline Muscles affected & 12 & 1 & 0.036 & 2 & 2 \\
\hline Wheelchair-bound & - & 1 & & 1 & - \\
\hline
\end{tabular}


the occurrence of distal muscle weakness in upper limbs was seen only in patients with MM cases (7/12 vs. $0 / 12)(P=0.037)$. Similarly, the lower limb distal muscles were involved predominantly in MM (12/12 vs. $1 / 12)(P=0.036)$ [Table 2]. There was no significant difference in gender, age of onset, duration of illness or in the CK values between the different phenotypic groups. The pattern of preferential muscle involvement was recorded. It was observed that in the upper limbs the pectoralis and biceps muscles were more severely affected than their antagonists and in the lower limbs iliopsoas, hip adductors, hamstrings and gastrocnemius were more affected than their corresponding antagonist group. This selectivity of muscle involvement was typical as described in limb girdle muscular dystrophies [Table 3]. The frequency and severity of the commonly affected muscles are depicted in Figure 5.

\section{Laboratory findings}

The mean CK value was $10033.8 \pm 9283 \mathrm{U} / \mathrm{l}$ (range 402-27460). Electromyography performed in all 28 patients showed myopathic features in the majority. Positive sharp waves in six (21.4\%), fibrillations in four (14.2\%), low-voltage-small motor unit potentials in $26(92.8 \%)$ and neurogenic in two (7.2\%) patients. Motor conductions had shown reduced compound muscle action potentials in the weak and atrophic muscles, sensory conductions were normal. The muscle biopsy on routine histopathology showed predominant dystrophic changes. In addition neurogenic features,

\begin{tabular}{|c|c|}
\hline & $\begin{array}{l}\text { Table 3: Selectivity pattern of muscle involvement in } 28 \text { patients } \\
\text { with dysferlinopathy }\end{array}$ \\
\hline $\begin{array}{l}\text { Selectivity pattern (muscle names) } \\
\text { Upper limbs }\end{array}$ & $\mathbf{N}(\%)$ \\
\hline \multicolumn{2}{|l|}{ Shoulder girdle $(n=15)$} \\
\hline Deltoid > Pectoralis & $3(20.0)$ \\
\hline Pectoralis $>$ Deltoid & $10(44.4)$ \\
\hline Deltoid = Pectoralis & $2(13.3)$ \\
\hline \multicolumn{2}{|l|}{$\operatorname{Arm}(n=14)$} \\
\hline Biceps > Triceps & $11(78.6)$ \\
\hline Triceps > Biceps & $2(14.3)$ \\
\hline Biceps = Triceps & $1(6.66)$ \\
\hline \multicolumn{2}{|l|}{ Lower limbs } \\
\hline \multicolumn{2}{|l|}{ Pelvic girdle $(n=26)$} \\
\hline Iliopsoas > Gluteus Max & $18(69.2)$ \\
\hline Guteus Max > lliopsoas & $5(19.2)$ \\
\hline Gluteus Max = Iliopsoas & $3(11.5)$ \\
\hline \multicolumn{2}{|l|}{ Thigh $(n=25)$} \\
\hline Adductors $>$ Abductors & $18(72.0)$ \\
\hline Abductors $>$ Adductors & 0 \\
\hline Adductors $=$ Abductors & $7(28.0)$ \\
\hline \multicolumn{2}{|l|}{ Thigh $(n=24)$} \\
\hline Hamstrings > Quadriceps & $15(62.5)$ \\
\hline Quadriceps $>$ Hamstrings & $4(16.6)$ \\
\hline Hamstrings = quadriceps & $5(20.8)$ \\
\hline \multicolumn{2}{|l|}{$\operatorname{Leg}(n=17)$} \\
\hline Gastroc $>$ Tib anterior & $9(52.9)$ \\
\hline Tib anterior $>$ Gactrocnemius & $4(23.5)$ \\
\hline Gastroc $=$ Tib anterior & $4(23.5)$ \\
\hline
\end{tabular}

Max, maximus; Gastroc, gastrocnemius; Tib, tibialis, > = more weaker/affected; $=$ equally affected inflammatory infiltrates were also noted. The detailed findings on histopathology are depicted in Figure 6. Immunostaining showed evidence of normal staining pattern for dystrophin $(1,2,3)$, sarcaglycans $(\alpha, \beta, \gamma, \delta)$, dystroglycans and merosin, except for total absence of dysferlin staining [Figure 7].

\section{Discussion}

This study reports 28 patients with immunochemically confirmed dysferlinopathy, with $43 \%$ of the 28 having classical MM and an equal number having LGMD2B, two each had proximodistal form and tibial muscular dystrophy type. Our diagnosis was based on the lack of dysferlin expression on muscle IHC. We could not perform immunoblot analysis and there is a possibility of having missed primary calpainopathies with secondary dysferlin deficiency. In patients with MM phenotype the weakness typically started in calf muscles and later spread to other regions while in LGMD2B the weakness classically started in lower limb proximal muscles. Of a total of 120 patients diagnosed to have muscular dystrophy excluding dystrophinopathy and seen between 2005 and 2007, dysferlinopathy was diagnosed in $23 \%$. In the remaining, sarcoglycanopathy occurred in $18.3 \%$ and the rest did not demonstrate any deficiency to the various antibodies used. In a study from the US, among 266 muscle biopsies evaluated, dysferlinopathy comprised 18\%.[16] Among 166 Brazilian patients with AR LGMD 24 (14\%) had dysferlinopathy. ${ }^{[17]}$ Of 1420 Japanese patients with muscular dystrophy LGMD formed the second largest category (19\%) and of these dysferlinopathy comprised $18 \%{ }^{\left[{ }^{[18]}\right.}$ Compared to these reports, among our patients with LGMD, dysferlinopathy formed 23\%, which was slightly higher. Probably the percentage would have been lower if immunoblot was performed as in previous studies. Thus, dysferlinopathy is not an uncommon disorder among our cases of LGMD. The presentation of distal phenotype of MM and LGMD2B phenotype among our patients were similar to those reported earlier. ${ }^{[6,19]}$ In the original description by Miyoshi et al., all patients had onset of disease at or before 30 years of age and the majority (14 of 17) had onset before 20 years of age. ${ }^{[3]}$ In the present series the majority (92\%) of our patients with $\mathrm{MM}$ also had an age of onset before 30 years and $50 \%$ of these had onset before 20 years. Our findings were also similar to the Dutch series on MM where the onset was as early as 13 years but ranged up to the sixth decade. ${ }^{[6]}$ However, none of our patients had onset after the fourth decade. In a report from Japan the mean age of onset for MM was 22 years and for LGMD2B it was 26 years.

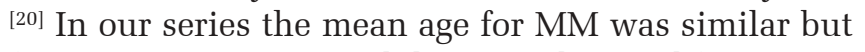
for LGMD2B it was much lower and ranged from 11 to 28 years of age and this is similar to that described by Linssen et al. and Mahjneh et al. ${ }^{[6,19]}$ In another report 


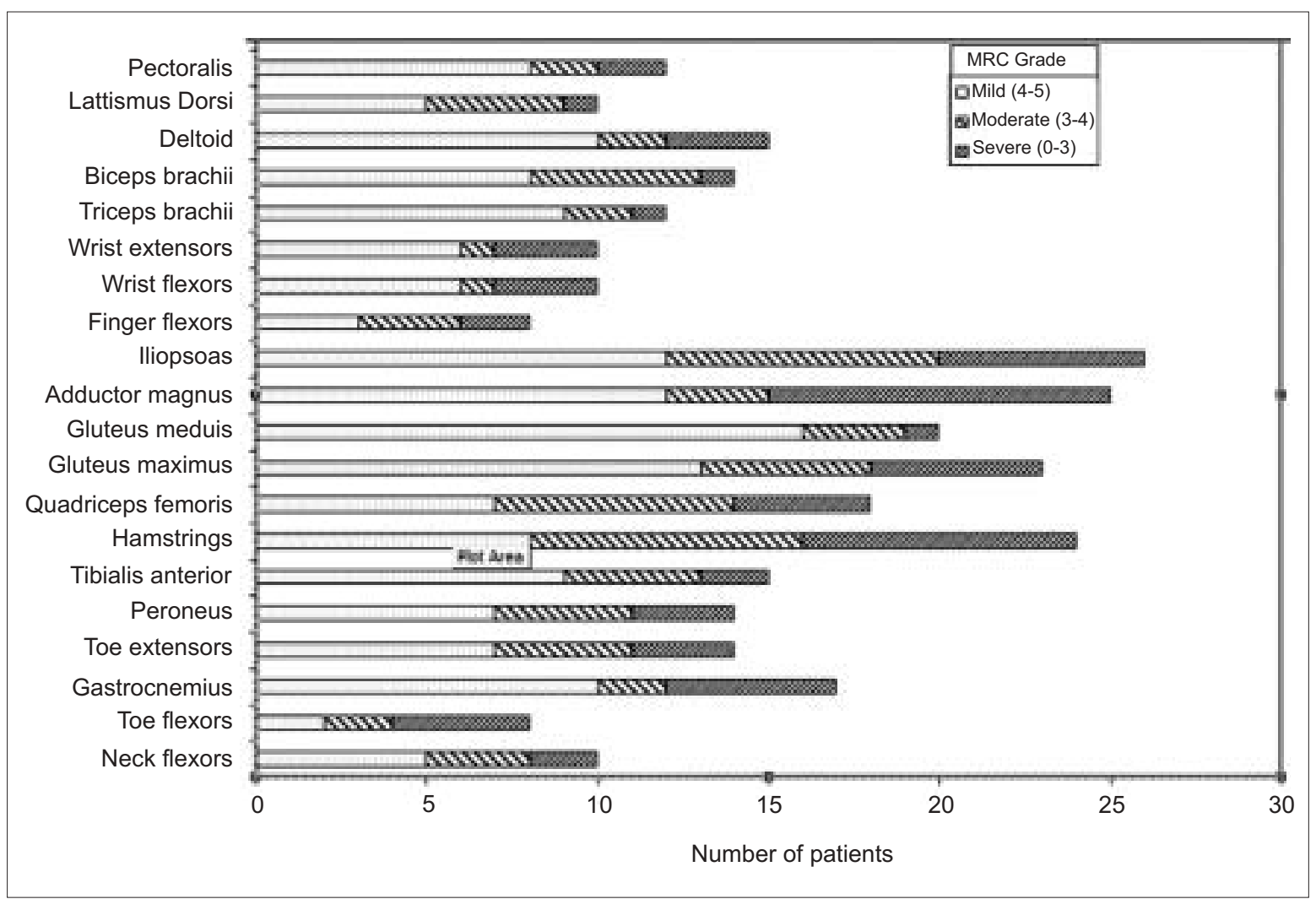

Figure 5: Bar diagram depicting the frequency and severity of involvement of commonly affected muscles

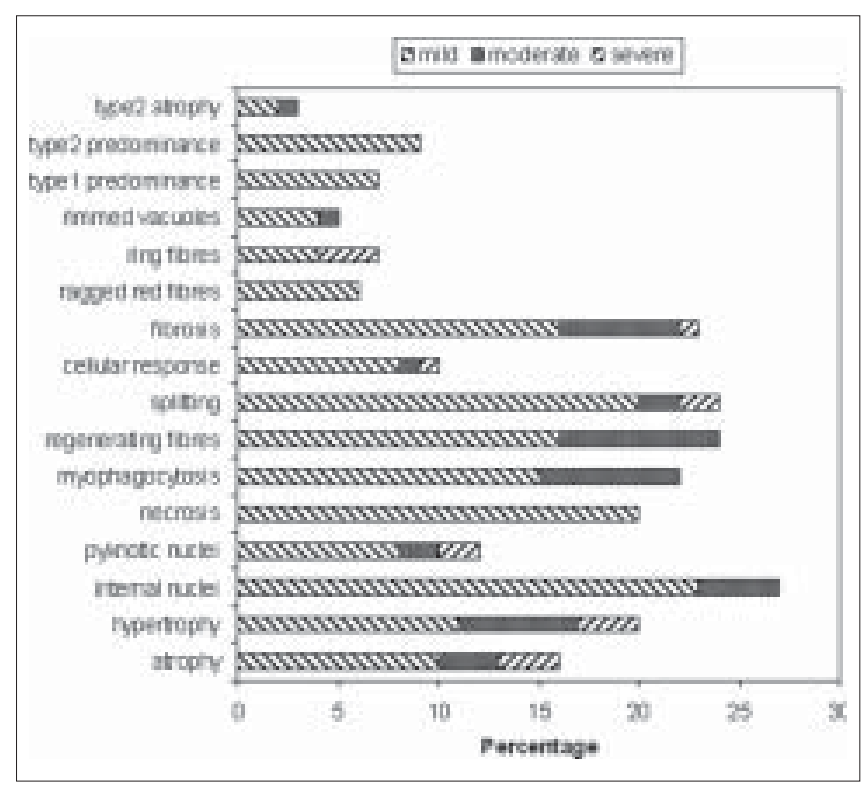

Figure 6: Bar diagram depicting the distribution of various pathological findings

from India, among MM patients the onset was between 9 and 28 years. ${ }^{[21]}$

About 50\% of our patients with MM had upper limb proximal muscle wasting and weakness at an early course of the illness within 12 years of onset. In the Dutch series also in $54 \%$ of patients the deltoid and biceps were atrophied. ${ }^{[6]}$ However, Miyoshi et al., in 1986, described involvement of proximal muscles of upper limbs, only in advanced stage of the disease. ${ }^{[3]}$ Nine of the 28 patients in our series had distal muscle weakness and wasting including small muscles of the hands. Only two of our patients were wheelchair-bound at the time of evaluation, one with proximodistal form at 15 years after onset and one with LGMD2B at nine years after onset. The age at onset and gender had no bearing on the progression of illness.

Creatine kinase was markedly elevated in the majority of our patients, but a few patients had elevation only up to four times the upper limit value. A relatively low CK level with minimum of $627 \mathrm{IU} / \mathrm{l}$ has been shown to occur in confirmed cases of LGMD2B from Japan ${ }^{[20]}$ and value as low as $751 \mathrm{IU} / \mathrm{l}$ in the Dutch series. ${ }^{[6]}$ Muscle pain was reported in $46 \%$ of our patients but none had painful muscle swellings or rhabdomyolysis as mentioned in an earlier report. ${ }^{[22]}$ The muscle biopsy findings were essentially similar to the previously described findings by Barohn etal. ${ }^{[7]}$ Majority of the biopsies showed dystrophic process but signs of neurogenic atrophy were also noted in four. Mononuclear cell infiltrates surrounding necrotic fibers was seen in seven biopsies.

Although classical MM and LGMD2B phenotype are most common in dysferlinopathies, a spectrum of various phenotypes ranging from isolated hyperCKaemia 


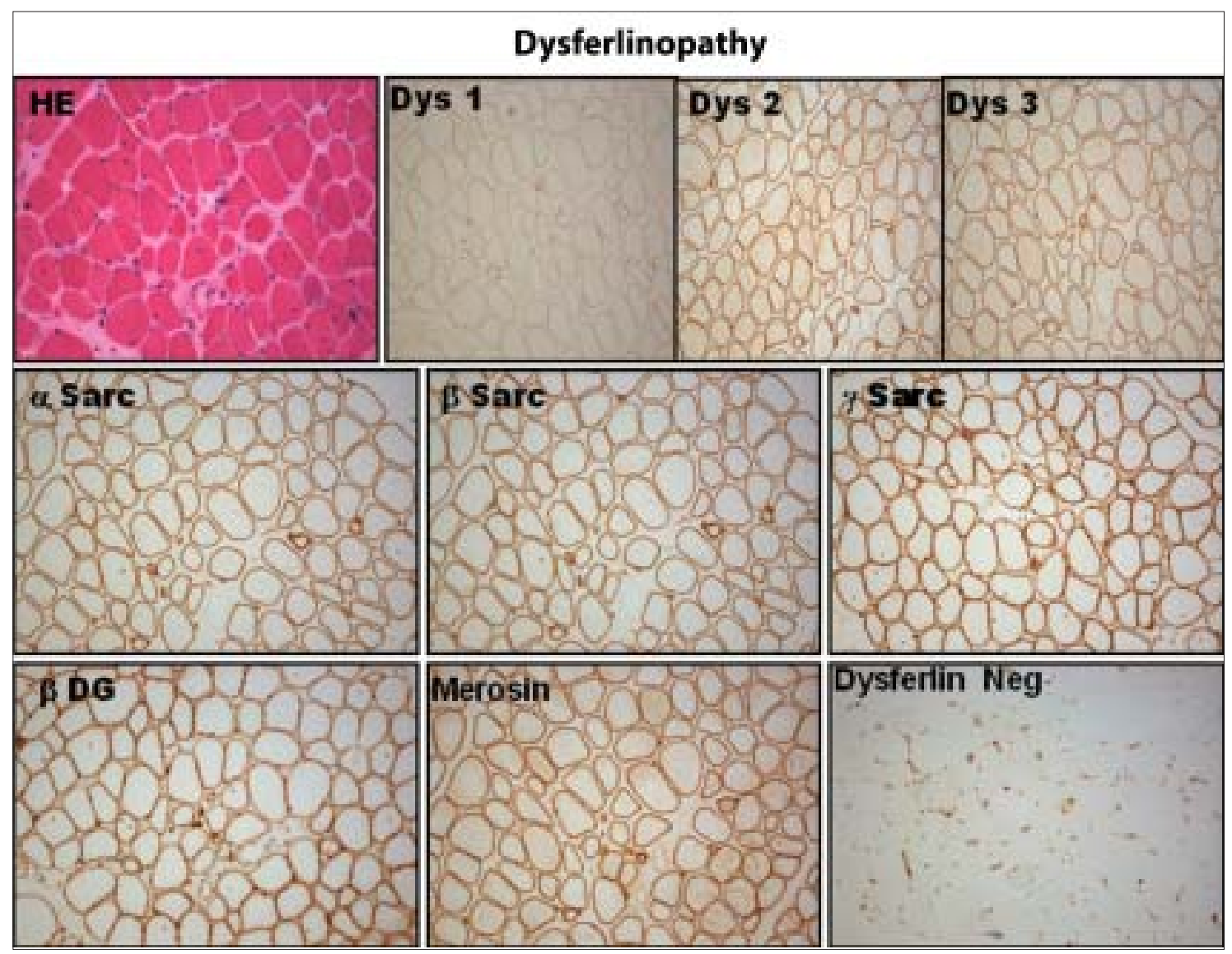

Figure 7: Skeletal muscle tissue showing dystrophic features (HE). Immunolabeling to dysferlin shows total absence while the remaining are preserved (240.) (HE - Hematoxylin and Eosin; Dys- Dystorphin; Sarc- Sarcoglycan; DG- Dystroglycan, Neg- Negative)

to severe proximodistal phenotype has been observed. ${ }^{[22,23]}$ In a report from France, the proximodistal form has been reported to occur in as high as $35 \%$ of dysferlinopathies while the classical MM phenotype was seen in only $50 \%{ }^{[24]}$ Only two of our patients had a severe proximodistal form among the 28 patients. Recently, in MM a characteristic appearance in the upper back and shoulders was termed as calf heads on trophy sign. This is observed on the upper back and shoulders when patients are made to raise their arms with shoulders abducted and elbows flexed to $90^{\circ} .^{[21]}$ Following this report we have been keenly examining our patients for this clinical sign but have not yet observed this finding.

Intrafamilial and interfamilial variability is a known aspect in dysferlinopathies. Weiler et al., in 1996 described the Canadian aboriginal kindred with nine patients and seven had weakness in the proximal muscles of lower limbs in the early or late teens and also distal weakness on examination later. All except one was wheelchair-bound by age $25-42$ years. ${ }^{[25]}$ The large Avar family reported from Caucasus by Illarioshkin et al., is also heterogeneous. Thus there was a variable presentation and progression. ${ }^{[4]}$ A study among
Libyan Jews showed that clinical features in dysferlin deficiency were heterogeneous even in the same family, $50 \%$ had features of MM while in the remaining it was of LGMD type. ${ }^{[26]}$ Another family reported by Lui et al., also had a variable phenotype with identical dysferlin mutation. ${ }^{[15]}$ Our patients had a mean duration of illness of 6.4 years and all except two were ambulant at the time of evaluation. They also had a variable presentation and course of illness and showed marked intrafamilial heterogeneity. Thus, similar to earlier studies ${ }^{[4,6,16,27]}$ we observed phenotypic heterogeneity among our patients. No clear explanation exists for the remarkable inter and intrafamilial variation of dysferlinopathies.

While MM most commonly causes a slowly progressive muscular dystrophy, it is known that rapid progression does occur with one-third of a Dutch series needing a wheelchair for mobility outside from about 10 years after onset. ${ }^{[6]}$ Among our patients at the end of a mean duration of 6.4 years all were ambulant. A longer followup on these patients would be necessary to assess the onset of disability.

It is also reported that patients in whom dysferlin mutations have been described, present with a predominantly anterior distal involvement rather than 
the posterior distal involvement which is characteristic of MM. ${ }^{[10,15]}$ In our series two of the 28 patients had onset like tibial muscular dystrophy which later progressed to involve the proximal and posterior leg muscles, but the tibial muscles continued to be more severely affected than the posterior leg muscles. Thus, as postulated, additional factors, genetic or non-genetic may contribute to the pattern of muscle involvement in dysferlinopathies. In one of our families two of the three sisters had LGMD2B and interestingly all three had multinodular goiter with thyrotoxicosis. This association has not been reported earlier. The importance or relevance of this is not known.

Diagnosis of dysferlin-related muscular dystrophy should be considered in any patient with a muscular dystrophy syndrome, occurring in late teens or adult life. Further, genetic diagnosis is important, as there is potential for prenatal diagnosis.

\section{Acknowledgments}

We immensely thank Prof. Andoni Urtizberea, Director ENMC for providing us with the Dysferlin antibody.

\section{References}

1. Miyoshi K, Saijo K, Kuryu H, Tada Y, Otsuka Y, Oshima Y, \& al. Four cases of distal myopathy in two families [in Japanese]. Jpn J Hum Genet $1967 ; 12: 113$

2. Miyoshi K, Iwasa M, Kawai H, Sasaki N, Kusaka K, Yagita M, \& al. Autosomal recessive distal dystrophy: A new type of distal muscular dystrophy observed characteristically in Japan [in Japanese]. Jpn J Clin Med 1977;35:3922-8.

3. Miyoshi K, Kawai H, Iwasa M, Kuska K, Nishino H. Autosomal recessive distal muscular dystrophy as a new type of progressive muscular dystrophy: Seventeen cases in eight families including an autopsied case. Brain 1986;109:31-54.

4. Illarioshkin SN, Ivanova-Smolenskaya IA, Tanaka H, Vereshchagin NV, Markova ED, Poleshchuk VV, \& al. Clinical and molecular analysis of a large family with three distinct phenotypes of progressive muscular dystrophy. Brain 1996;119:1985-90.

5. Mahjneh I, Vannelli G, Bushby K, Marconi GP. A large inbred Palestinian family with two forms of muscular dystrophy. Neuromuscul Disord 1992;2:277-83.

6. Linssen WH, Notermans NC, van der Graaf Y, Wokke JH, Van Doorn PA, Howeler CJ, \& al. Miyoshi-type distal muscular dystrophy: Clinical spectrum in 24 Dutch patients. Brain 1997;120:1989-96.

7. Barohn RJ, Miller RG, Griggs RC. Autosomal recessive distal dystrophy. Neurology 1991;41:1365-70.

8. Bashir R, Strachan T, Keers S, Stephenson A, Mahjneh I, Marconi G, \&al. A gene for autosomal recessive limb-girdle muscular dystrophy maps to chromosome 2p. Hum Mol Genet 1994;3:455-7.

9. Mahjneh I, Passos-Bueno MR, Zatz M, Vainzof M, Marconi G, Nashef L,
\& al. The phenotype of chromosome 2 p-linked limb girdle muscular dystrophy. Neuromuscul Disord 1996;6:483-90.

10. Bushby KM. Making sense of the limb-girdle muscular dystrophies. Brain 1999;122:1403-20.

11. Ho M, Gallardo E, McKenna-Yasek D, Luna ND, Illa I, Brown RH Jr. Diagnostic assay for limb girdle muscular dystrophy2B and Miyoshi myopathy. Ann Neurol 2002;51:129-33.

12. Bejaoui K, Hirabayashi K, Hentati F, Haines JL, Ben Hamida C, Belal S, \& al. Linkage of Miyoshi myopathy (distal autosomal muscular dystrophy) locus to chromosome 2p12-14. Neurology 1995;45:768-72.

13. Bashir R, Keers S, Strachan T, Passos-Bueno R, Zatz M, Weissenbach J, eal. Genetic and physical mapping at the limb-girdle muscular dystrophy locus (LGMD2B) on chromosome 2p. Genomies 1996;33:46-52.

14. Bashir R, Britton S, Strachan T, Keers S, Vafiadaki E, Lako M, etal A gene related to Caenorhabtidis elegans spermatogenesis factor fer-1 is mutated in limb-girdle muscular dystrophy type 2B. Nat Genet 1998;20:37-42.

15. Liu J, Aoki M, Illa I, Wu C, Fardeau M, Angelini C, \& al. Dysferlin, a novel skeletal muscle gene, is mutated in Miyoshi myopathy and limb girdle muscular dystrophy. Nat Genet 1998;20:31-6.

16. Moore SA, Shilling CJ, Westra S, Wall C, Wicklund MP, Stolle C, \& al. Limb-girdle muscular dystrophies in the United states. J Neuropathol Exp Neurol 2006;65:995-1003.

17. Vainzof M, Anderson LV, MeNally EM, Davis DB, Faulkner G, Valle G, \& al. Dysferlin protein analysis in limb-girdle muscular dystrophies. J Mol Neurosei 2001;17:71-80.

18. Sunada Y. Limb-girdle muscular dystrophy: Update. Rinsho Shinkeigaku 2004;44:995-7.

19. Mahjneh I, Matconi G, Bushby K, Anderson LV, Tolvanen-Mahjneh H, Somer H. Dysferlinopathy (LGMD2B): A 23 year follow-up study of 10 patients homozygous for the same frameshifting dysferlin mutations. Neuromuscular Disord 2001;11:20-6.

20. Aoki M, Takahashi T. Mutational and clinical features of Japanese patients with dysferlinopathy (Miyoshi myopathy and limb girdle muscular dystrophy type 2B. Rinsho Shinkeigaku 2005;45:938-42.

21. Pradhan S. Calf-Head sign in miyoshi myopathy. Arch Neurol 2006;63:1414-7.

22. Nyugen K, Bassez G, Bernard R, Krahn M, Labelle V, FigarellaBranger D, \& al. Dysferlin mutations in LGMD2B, Miyoshi myopathy and atypical dysferlinopathies. Hum Mutat 2005;26:165.

23. Galassi G, Rowland LP, Hays AP, Hopkins LC, Di Mauro S. High serum levels of creatine kinase: asymptomatic prelude to distal myopathy. Muscle Nerve 1987;10:346-50.

24. Nyugen K, Bassez G, Krahn M, Bernard R, Laforet P, Labelle V, đ al. Phenotypic study in 40 patients with dysferlin gene mutations: high frequency of atypical phenotypes. Arch Neurol 2007;64:1176-82.

25. Weiler T, Greenberg CR, Nylen E, Halliday W, Morgan K, Eggertson D, \& al. Limb- girdle muscular dystrophy and Miyoshi myopathy in an aboriginal Canadian kindred map to LGMD2B and segregate with the same haplotype. Am J Hum Genet 1996;59:872-8.

26. Agrov Z, Sadeh M, Mazor K, Soffer D, Kahana E, Eisenberg I, \& al. Muscular dystrophy due to dysferlin deficiency in Libyan Jews. Clinical and genetic features. Brain 2000;123:1229-37.

27. Angelini C. Limb-girdle muscular dystrophies: Heterogeneity of clinical phenotypes and pathogenetic mechanisms. Acta Myol 2004;23:130-6.

Accepted on 06-03-2008

Source of Support: Nil, Conflict of Interest: None declared. 